to believe that some of the time spent on dogma might not more profitably be spent in making prospective parsons familiar with the broad paths of science; courses in social anthropology might be of practical concern to future missionaries.

That the strengthening of science and engineering education cannot be undertaken except by strengthening the country's general educational system is a point well made by the Committee and underlined by the President himself. In Britain the direction is right, but it may well be considered whether the pace is rapid enough. There are still too many black-listed schools. Hopelessly overcrowded classes in primary schools present teachers with problems in which education is replaced by mass instruction. The high hopes held out for secondary modern schools have not been fulfilled. County colleges remain a dream, and, because of the shortage and quality of staff at many technical institutions, the facilities available for many day-release students often account for appalling wastages between the first and last years of City and Guilds and National Certificate courses. Shortages of competent lecturers in mathematics and science at teachers' training colleges have led to a vicious eircle which results in the bad teaching of mathematics and science in many junior schools. The lack of hostels for students in senior technical colleges and universities and consequent living in overcrowded lodgings makes many university lives narrow and drab.

These are some of the features of the British educational system which should be examined when too much is made of our advances. The report of the President's Advisory Committee should have both a stimulating and salutary effect in Great Britain, in the United States and in the whole Western world.

\section{EXTREMELY HIGH TEMPERATURES}

\section{Conference on Extremely High Temperatures}

Boston, Massachusetts, March 18-19, 1958. Edited by Dr. Heinz Fischer and Lawrence C. Mansur. (Sponsored by Electronics Research Directorate, Air Force Cambridge Research Center.) Pp. xi+258. (New York: John Wiley and Sons, Inc.; London : Chapman and Hall, Ltd., 1958.) 78s. net.

7 THIS volume is an account of the first conference on extremely high temperatures sponsored by the U.S. Air Force Cambridge Research Center, under the chairmanship of Dr. Heinz Fischer. At first sight it looks as though the U.S. Air Force were in competition with the Atomic Energy Commission in supporting thermonuclear research at a time when those activities of the Commission called "Project Sherwood" were all classified, and there are clear indications that investigators under the Air Force contract are covering some of the ground the Atomic Energy Commission's scientists had covered long before. But the conference was based on a broader realm of science than thermonuclear research; it einbraced the study of high-current arcs and materials capable of withstanding extremely high temperatures, with the result that all subjects were treated rather sketchily and a specialist reader is likely to be interested in only one or two papers in the volume.
Several papers deal with the development of very high speeds of small pockets of gas driven by shock waves, work not unlike the large quantity of work reported by Post and others from Livermore. Janes and Patrick accelerated an annulus of gas between eylinders to $3 \times 10^{7} \mathrm{~cm}$. $/ \mathrm{sec}$. with currents rising at $10^{6} \mathrm{amp} . / \mu$ sec., and Bostick describes the propulsion of a small volume of plasma at $2 \times 10^{7} \mathrm{~cm}$. $/ \mathrm{sec}$. ejected from a deuterium-loaded titanium gun, while Nadig and Bohn give a preliminary account of the shooting of a plasma of oxploded wire between long copper plates.

Several papers deal with the study of high-powered arcs at atmospheric and higher pressures, ares dissipating $1,000 \mathrm{~kW}$. of d.c. power, stabilized by a water sheath such as was originally developed at Kiel. The plasma of gas emerges from the arc chamber at temperatures up to 15,000 degrees and is constricted to some extent by the electrical pinch-effect. Ghai mentions that the most serious limitation to the application of these very high-intensity plasmas has been the erosion of electrodes, and states that in the past year such erosion has been reduced a hundredfold, but unfortunately he does not state how this has been achieved. Bonin and Price, on the other hand, present informative figures on the ablation and erosion of different materials-which might be used in rocket cones-when subjected to the plasmas from these ares.

A session on temperature measurement produced some valuable papers. Drummond outlined the microwave properties of high-temperature plasmas and showed that it should be possible to record with microwaves temperatures leading up to fusion. Pearce presented valuable calculations about the density of light-emitters deduced from the observed brightness across the diameter of a cylindrical light source, and two papers deal with the deduction of are temperatures from the hydrogen-line broadening.

There are several brief papers on energy storage, capacitative and inductive, and one by Finkelstein outlines the application of a 100,000-joule bank of condensers having specially low inductance (one millimicrohenry total) to develop a betatron field of up to 200,000 gauss over an orbit of $5 \mathrm{~cm}$. radius, to achieve the particle acceleration needed to disintegrate matter not into the 'fourth state', namely, electrons and protons, but into the 'fifth state', namely, nucleons and mesons. In this connexion Levine et al. review the problems encountered in generating magnetic fields up to 750,000 gauss for milliseconds. The article on the feasibility of thermonuclear propulsion sounds like science fiction and $\mathrm{my}$ reaction was "first catch your hare".

T. E. Allibone

\section{ELECTRON TECHNOLOGY}

\section{Electron Physics and Technology}

By Dr. J. Thomson and E. B. Callick. (Physical Science Texts.) Pp. xiv +527. (London: English Universities Press, Ltd., 1959.) 50s. not.

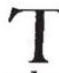

HE publishers say that this work is intended to provide a sound theoretical basis for the student who is pursuing an honours degree in either physics or electrical engineering. In fact, the authors seem to have cantered lightly over the fields of electron physies and elementary valve cireuits, skirting around 